This is the author's final, peer-reviewed manuscript as accepted for publication. The publisher-formatted version may be available through the publisher's web site or your institution's library.

\title{
Role of fault attributions and desire/effort/outcome expectations in children's anticipated responses to hypothetical peers with various undesirable characteristics
}

Mark A. Barnett, Tammy L. Sonnentag, Jennifer L. Livengood, Adrienne L. Struble, \& Taylor W. Wadian

\section{How to cite this manuscript}

If you make reference to this version of the manuscript, use the following information:

Barnett, M. A., Sonnentag, T. L., Livengood, J. L., Struble, A. L., \& Wadian, T. W. (2012). Role of fault attributions and desire/effort/outcome expectations in children's anticipated responses to hypothetical peers with various undesirable characteristics. Retrieved from http://krex.ksu.edu

\section{Published Version Information}

Citation: Barnett, M. A., Sonnentag, T. L., Livengood, J. L., Struble, A. L., \& Wadian, T. W. (2012). Role of fault attributions and desire, effort, and outcome expectations in children's anticipated responses to hypothetical peers with various undesirable characteristics. The Journal of Genetic Psychology: Research and Theory on Human Development, 173(3), 317-329.

Copyright: Copyright $\odot$ Taylor \& Francis Group, LLC

Digital Object Identifier (DOI): doi:10.1080/00221325.2011.610391

Publisher's Link: http://www.tandfonline.com/doi/abs/10.1080/00221325.2011.610391

This item was retrieved from the K-State Research Exchange (K-REx), the institutional repository of Kansas State University. K-REx is available at http://krex.ksu.edu 
Role of Fault Attributions and Desire/Effort/Outcome Expectations in Children's

Anticipated Responses to Hypothetical Peers with Various Undesirable Characteristics

Mark A. Barnett, Tammy L. Sonnentag, Jennifer L. Livengood,

Adrienne L. Struble, \& Taylor W. Wadian

Kansas State University

Citation:

Barnett, M. A., Sonnentag, T. L., Livengood, J. L., Struble, A. L., \& Wadian, T. W. (2012). Role of fault attributions and desire/effort/outcome expectations in children's anticipated responses to hypothetical peers with various undesirable characteristics. Journal of Genetic Psychology, 173, 317-329.

Address correspondence to Mark A. Barnett, Kansas State University, Department of

Psychology, Bluemont Hall, 1100 Mid-Campus Drive, Manhattan, KS 66506, USA;

barn@ksu.edu (e-mail address). 


\begin{abstract}
A total of 137 third- through eighth-grade students were asked to respond to a series of statements concerning six male peers described as having various undesirable characteristics (i.e., poor student, poor athlete, extremely overweight, extremely aggressive, extremely shy, or having the symptoms of ADHD). The aggressive peer and the overweight peer consistently elicited the least favorable reactions from the children. For all six peers included in the study, the more strongly the children agreed that a peer was at fault for his undesirable characteristic, the less favorably they anticipated responding to that peer. In contrast, the children's expectations concerning a peer's desire to change, effort to change, and success in changing an undesirable characteristic were generally unrelated to their anticipated responses to that peer. The children demonstrated the general belief that desire backed by effort leads to success in overcoming an undesirable characteristic, but lack of effort leads to failure regardless of the peer's desire or lack of desire to change the characteristic.
\end{abstract}

Key words: desire/effort/outcome expectations, fault attributions, peer evaluation, social cognition 
Children tend to respond in a relatively negative manner toward peers who are perceived as deviant or deficient in their appearance, ability, or behavior. For example, children have been found to respond more negatively to peers who stutter (Davis, Howell, \& Cook, 2002; Langevin, Bortnick, Hammer, \& Wiebe, 1998), have physical and intellectual disabilities (Nabors \& Keyes, 1995; Nowicki \& Sandieson, 2002), are shy and withdrawn (Coplan, Girardi, Findlay, \& Frohlick, 2007), are autistic (Campbell, 2006; Swaim \& Morgan, 2001), and have the symptoms of ADHD (Law, Sinclair, \& Fraser, 2007) than peers who are “typical” or “normal.” However, not all peers who are perceived as deviant or deficient are treated by children with the same level of disdain. Indeed, research has suggested that peers who are extremely aggressive and those who are obese are likely to receive especially unfavorable responses from children (e.g., Juvonen \& Weiner, 1993; Sonnentag, Barlett, Livengood, Barnett, \& Witham, 2009).

Although some aggressive peers may be held in relatively high regard by children who perceive them as socially prominent (e.g., leaders; Robertson et al., 2010) and as possessing peer-valued characteristics (e.g., toughness; Vaillancourt \& Hymel, 2006), it is not surprising that aggressive peers are generally evaluated negatively and rejected by children because of the fear and pain they cause others to experience (Coie \& Dodge, 1998). Whereas extremely aggressive peers elicit rejection from children because of their unpleasant interpersonal behaviors, the stigmatization of obese peers has its origins in what children, as young as three years old, deem to be an unpleasant appearance (Bell \& Morgan, 2000; Cramer \& Steinwert, 1998; Zeller, Reiter-Purtill, \& Ramey, 2008). As Puhl and Latner’s (2007) extensive review indicates, children's attributions about causality regarding obese peers’ appearance are also related to children's negative stereotyping and maltreatment of these peers. For example, in one study of fourth- through sixth-grade children (Tiggemann \& Anesbury, 2000) cited by these 
authors, the "children largely believed that obesity is under personal control, and the extent of perceived controllability was positively correlated with the degree of negative stereotyping" (p. 562). Puhl and Latner's (2007) review also demonstrated that children's stigmatization of obese peers can have a profoundly negative influence on the obese peers' psychological adjustment, and emotional and physical health.

Attributions of causality or fault appear to play an important role in children's unfavorable response, not only to obese peers, but to peers with a broad range of undesirable characteristics (e.g., Juvonen, 1991). For example, in a study (Sonnentag et al., 2009) assessing third- and sixth-grade students’ anticipated responses to hypothetical peers with a variety of undesirable characteristics (i.e., poor student, poor athlete, extremely overweight, extremely aggressive, extremely shy, having the symptoms of ADHD, having the symptoms of asthma), the more the children agreed that the peers were at fault for their characteristics, the more they tended to agree that they would tease those peers and the less they tended to agree that they would like or help those peers if they needed assistance. It is noteworthy that, in the Sonnentag et al. (2009) study, the children indicated that they anticipated responding more negatively to the extremely aggressive and extremely overweight peers, and they agreed more strongly that these individuals were at fault for their undesirable characteristic, than any of the other peer targets included in the study.

In addition to attributions of fault, children's reactions to a peer with an undesirable characteristic may be influenced by information concerning the peer's desire to change the characteristic, effort to change the characteristic, and success in changing the characteristic. In a recent study involving fifth- and sixth-grade students (Barnett, Livengood, Sonnentag, Barlett, \& Witham, 2010), the children anticipated responding more favorably to hypothetical peers who 
were successful in overcoming an undesirable characteristic than those who were unsuccessful. However, in both the success and failure conditions, peers who wanted to change and exerted effort to change were rated more favorably than were peers who reported no effort to change an undesirable characteristic. For peers whose failure to change an undesirable characteristic was associated with no effort to change, those who expressed a desire to change were rated more favorably than those who expressed no desire to change.

In summary, children’s responses to peers with undesirable characteristics appear to be influenced by both their attributions concerning the peers’ responsibility for having the characteristic (Juvonen, 1991; Puhl \& Latner, 2007; Sonnentag et al., 2009), and their expectations concerning the peers' desire to change, effort to change, and success in changing the characteristic (Barnett et al., 2010). However, no study to date has assessed the relative impact of children's fault attributions and desire/effort/outcome expectations on their anticipated responses to peers with various undesirable characteristics. This gap in the literature was the major issue addressed in the present study. A secondary purpose of the present study was to determine (a) which desire/effort/outcome patterns children expect peers with undesirable characteristics to demonstrate and (b) whether these expectations are influenced by the specific “deviance or deficiency” the peers possess.

\section{Participants}

\section{Method}

A total of 137 third- through eighth-grade students (74 boys, 63 girls; $M$ age $=10.64$ years, $S D=1.71$ years) attending a soccer camp in a small town in central Wisconsin participated in small groups. The children were predominately White and from middle-class backgrounds. Institutional Review Board (IRB) approval was obtained for this study, and each child's parent or legal guardian signed an informed consent form prior to the child's participation in the 
investigation. The children also provided written consent to participate at the beginning of each group session and were verbally debriefed upon completion of the session.

\section{Materials and Procedure}

The participants were asked to rate, on six separate questionnaires, their perceptions of six male peers described as having various undesirable characteristics (i.e., poor student, poor athlete, extremely overweight, extremely aggressive, extremely shy, having the symptoms of ADHD; adapted from Barnett et al., 2010 and Sonnentag et al., 2009; see descriptions in Table 1). ${ }^{1}$ Specifically, the children rated on a 6-point scale (from $1=$ strongly disagree to $6=$ strongly $<$ Insert Table \#1 about here> agree) how much they disagreed or agreed that (a) the undesirable characteristic is the peer's fault, (b) they would anticipate responding to the peer in a favorable manner (i.e., like, not tease, help; $\alpha$ s for the aggregate scores ranged from .63 to .86 for the six undesirable characteristics ${ }^{2}$ ), and (c) the peer would want to change (Desire; D), would try to change (Effort; E), and would succeed in changing the characteristic (Outcome; O). In addition, the children rated (on the same 6-point scale) how much they disagreed or agreed that each peer would respond to his undesirable characteristic with each of six D/E/O patterns (D/E/Success, D/E/Failure, D/NoE/S, D/NoE/F, NoD/NoE/S, NoD/NoE/F). ${ }^{3}$

\section{Results}

A series of 2 (Gender) x 2 (Age Group) x 6 (Characteristic) ANOVAs was conducted on the children's ratings of their perceptions of the six peers with undesirable characteristics. ${ }^{4}$ These analyses revealed that the extremely aggressive peer and the extremely overweight peer were rated significantly higher on Fault, and significantly lower on Anticipated Response, Desire, Effort, and Outcome, than the four other peers with undesirable characteristics (see Table 2). 
$<$ Insert Table \#2 about here $>$

Post hoc analysis of the significant Gender x Characteristic interaction for Anticipated Response, $F(5,665)=2.74, p<.05$, revealed that the girls anticipated responding more favorably than did the boys to all of the peers with undesirable characteristics except the extremely aggressive peer and the extremely overweight peer. For the latter two peers, the ratings of the girls and boys did not differ significantly from one another (see Table 3).

$<$ Insert Table \#3 about here $>$

A series of hierarchical regressions was conducted to assess the relative impact of the children's fault attributions and desire/effort/outcome expectations on their anticipated responses to the six peers with undesirable characteristics. Step 1 in all of the regressions included the participants' gender and age in months and step 2 included the children's ratings of Fault, Desire, Effort, and Outcome. Paralleling the pattern of results for the significant interaction of participant gender and characteristic presented above and in Table 3, the $R^{2}$ at Step 1 and the $\beta$ for participant gender were significant (with the girls anticipating responding more favorably than the boys) for all of the peers with undesirable characteristics except the extremely aggressive peer and the extremely overweight peer (significant $R^{2}$ s ranging from .05 to .19, all ps $<.05$; significant $\beta$ s ranging from .24 to .45, all $p s<.01$ ). The $\beta$ for participants' age in months was not significant in any of the six regression analyses.

The $\Delta R^{2}$ at Step 2 and the $\beta$ for ratings of Fault were significant for all of the regressions ( $\Delta R^{2}$ ranging from .28 to .42, all $p s<.001 ; \beta$ s ranging from -.38 to -.66, all $p s<.001$ ). Therefore, for all six peers included in the study, the more strongly the children agreed that a peer was at fault for his undesirable characteristic, the less favorably they anticipated responding to that peer. In contrast to the robust findings for ratings of fault, (a) the more strongly the 
children agreed that the poor student would desire to change, the more favorably they anticipated responding to this peer $(\beta=.34, p<.05)$, (b) the more strongly the children agreed that the peer with the symptoms of ADHD would exert effort to change, the more favorably they anticipated responding to this peer $(\beta=.36, p<.05)$, and (c) the extent to which the children agreed that the peers would succeed in changing their undesirable characteristic was unrelated to their ratings of their anticipated response to all six peers.

Finally, a series of 2 (Gender) x 2 (Age Group) x 6 (Characteristic) x 6 (D/E/O Pattern) ANOVAs was conducted on the children's ratings of the extent to which they disagreed or agreed that each peer would respond to his undesirable characteristic with each of the six D/E/O patterns described earlier. This analysis revealed that the children agreed much more strongly that the peers would respond to having an undesirable characteristic with D/E/S $(M=5.24$; $S D=.44), \mathrm{D} / \mathrm{NoE} / \mathrm{F}(M=5.03 ; S D=.52)$, or $\mathrm{NoD} / \mathrm{NoE} / \mathrm{F}(M=5.67 ; S D=.29)$ patterns than with D/E/F $(M=2.23 ; S D=.59)$, D/NoE/S $(M=1.65 ; S D=.46)$, or NoD/NoE/S patterns $(M=1.46 ; S D=.35), F(5,665)=2436.36, p<.001$. However, this main effect of Pattern was qualified by a significant Characteristic x Pattern interaction, $F(25,3325)=30.40, p<.001$. Post hoc analysis of this interaction revealed that the children agreed less strongly that desire combined with effort would lead to success (D/E/S), and more strongly that desire combined with effort would lead to failure (D/E/F), for the extremely aggressive peer and the extremely overweight peer than for peers with any other undesirable characteristic (see Table 4). For the $<$ Insert Table \#4 about here>

four remaining patterns of response (D/NoE/S, D/NoE/F, NoD/NoE/S, NoD/NoE/F), no significant differences were found among the mean ratings of the six peers with an undesirable characteristic. 


\section{Discussion}

Consistent with the results of our prior study (Sonnentag et al., 2009), the children anticipated responding least favorably to the extremely aggressive peer and the extremely overweight peer, and they attributed more fault to them for their undesirable characteristics, than peers described as a poor student, poor athlete, extremely shy, or as having the symptoms of ADHD. In addition, the children in the present study rated the aggressive peer and the overweight peer significantly lower than the four other peers on wanting to change, exerting effort to change, and likelihood of changing their undesirable characteristic. Thus, the children's heightened devaluation of the extremely aggressive peer and the extremely overweight peer appears to extend beyond beliefs concerning their responsibility for the onset of their undesirable characteristics (Juvonen, 1991; Sonnentag et al., 2009) to beliefs concerning their responsibility for the perpetuation of their undesirable characteristics. It is noteworthy that although girls tend to be more accepting of peers who are different or deficient on some dimensions than are boys (Killen, Crystal, \& Watanabe, 2002; Townsend, Wilton, \& Vakilirad, 1993; Whalen, Henker, Dotemoto, \& Hinshaw, 1983; four of the six peers with undesirable characteristics in the present study), the girls’ greater “tolerance” did not extend to peers who were described as extremely aggressive or extremely overweight in the present study.

The more the children attributed fault to all six peers for their undesirable characteristics, the less favorably they anticipated responding to the peers. In contrast, the children's expectations concerning a peer's desire to change (significant positive relation for the poor student only), effort to change (significant positive relation for the peer with the symptoms of ADHD only), and success in changing an undesirable characteristic (no significant relation for 
any peer) were generally unrelated to their anticipated response to the peers. Although the isolated significant findings for desire and effort may be spurious and defy interpretation, it is clear that the children's fault attributions played a larger role than the children's desire/effort/outcome expectations in their anticipated responses to the peers with undesirable characteristics. The heightened importance of the children's fault judgments in their anticipated responses to peers with undesirable characteristics is consistent with attribution research (e.g., Juvonen, 1991; Weiner, 1986) demonstrating that individuals who are perceived as responsible for unpleasant personal circumstances due to negligence, laziness, or negative intent tend to be devalued and treated relatively harshly. Furthermore, children's attributions concerning the peers' fault for their undesirable characteristics may reflect their beliefs about the peers' responsibility for both the onset and perpetuation of these characteristics. Thus, the children's desire/effort/outcome expectations may have been considered as merely one aspect of, and may have been statistically “trumped by,” the children’s fault attributions in regression analyses exploring their anticipated responses to these peers. ${ }^{5}$

The children's responses to the six potential D/E/O patterns reflect the general belief that desire backed by effort leads to success rather than failure, but lack of effort leads to failure rather than success, regardless of the peer's desire or lack of desire to change the undesirable characteristic. Stated simply, the children appear to believe that the desire to change combined with the exertion of effort to change is key to a peer overcoming an undesirable characteristic. However, consistent with the heightened denigration of the extremely aggressive peer and the extremely overweight peer, the children appear less confident that this "recipe for success" will be demonstrated by peers with these specific undesirable characteristics. 
Future research. In the present study, the data that the child-participants generated were limited to paper-and-pencil responses to hypothetical male peers described as having various undesirable chracteristics. Although the use of hypothetical peers as targets of children's selfreported attitudes and behavioral intentions is a common methodological approach for research in this area (Coplan et al., 2007; Crothers, Linden, \& Kennedy, 2007; Juvonen, 1991; Law et al., 2007; Nabors \& Keyes, 1995), it is important to examine children’s interpersonal reactions to “atypical” male and female peers in more naturalistic settings. However, researchers taking a more ecologically valid approach must be extremely sensitive to the ethical issues that may arise when documenting children's attitudes and behaviors toward “real” peers that they (or their teachers) identify as deviant or deficient in their appearance, ability, or behavior.

A specific direction for future research that emerges from the present study involves the possibility that children may make distinct attributions about peers' fault for the onset and the perpetuation of their undesirable characteristics. Although providing children with information that particular peers were not personally responsible for the onset of their undesirable characteristics has generally proven ineffective in altering children's negative attitudes toward those peers (e.g., Anesbury \& Tiggemann, 2000; Bell \& Morgan, 2000), informing children that particular peers were personally responsible for making a positive change in their undesirable characteristics has been found to yield a relatively favorable response (Barnett et al., 2010). Individual studies are needed that systematically examine (a) children’s beliefs about peers’ responsibility for the onset and continuation (or modification) of their undesirable characteristics and (b) the role of those beliefs in children's attitudes and behaviors toward peers with various undesirable characteristics. 


\section{AUTHOR NOTES}

Mark A. Barnett is a professor in the Department of Psychology at Kansas State University. His research interests focus on the attitudes and behaviors associated with the social-emotional development of children and adolescents. Tammy L. Sonnentag is a doctoral student in the social-personality psychology program at Kansas State University. Her primary research interests concern the correlates and perceptions of individuals who engage in exceptional moral behaviors. Jennifer L. Livengood is a doctoral student in the social-personality program at Kansas State University and an assistant professor of psychology at Missouri Valley College. Her research interests involve the effects of maternal employment on children and the perception of women and mothers in various familial and employment situations. Adrienne L. Struble is a master's student in the Social Welfare Program at the University of Kansas. Her primary research interests focus on the roles and experiences of Court Appointed Special Advocate (CASA) volunteers. Taylor W. Wadian is a doctoral student in the social-personality program at Kansas State University. His primary research interests address how children's perception and evaluation of peers are influenced by the peers' association with one another and the reason for their association. 


\section{References}

Anesbury, T., \& Tiggemann, M. (2000). An attempt to reduce negative stereotyping of obesity in children by changing controllability beliefs. Health Education Research, 15, 145-152.

Barnett, M. A., Livengood, J. L., Sonnentag, T. L., Barlett, N. D., \& Witham, R. Y. (2010). Children's anticipated responses to hypothetical peers with undesirable characteristics: Role of peers' desire to change, effort to change, and outcome. The Journal of Genetic Psychology, 171, 262-269.

Bell, S. K., \& Morgan, S. B. (2000). Children’s attitudes and behavioral intentions toward a peer presented as obese: Does a medical explanation for the obesity make a difference? Journal of Pediatric Psychology, 25, 137-145.

Campbell, J. M. (2006). Changing children's attitudes toward autism: A process of persuasive communication. Journal of Developmental and Physical Disabilities, 18, 251-272.

Coie, J. D., \& Dodge, K. A. (1998). Aggression and anti-social behavior. In N. Eisenberg (Ed.), Handbook of child psychology: Social, emotional, and personality development ( $^{\text {th }}$ ed., pp. 779-862). New York: Wiley.

Coplan, R. J., Girardi, A., Findlay, L. C., \& Frohlick, S. L. (2007). Understanding solitude: Young children's attitudes and responses toward hypothetically socially withdrawn peers. Social Development, 16, 390-409.

Cramer, P., \& Steinwert, T. (1998). Thin is good, fat is bad: How early does it begin? Journal of Applied Developmental Psychology, 19, 429-451.

Crothers, I. R., Linden, M. A., \& Kennedy, N. (2007). Attitudes of children towards peers with acquired brain injury (ABI). Brain Injury, 21, 47-52. 
Davis, S., Howell, P., \& Cook, F. (2002). Sociodynamic relationships between children who stutter and their non-stuttering classmates. Journal of Child Psychology and Psychiatry and Allied Disciplines, 69, 141-158.

Juvonen, J. (1991). Deviance, perceived responsibility, and negative peer reactions. Developmental Psychology, 27, 672-681.

Juvonen, J., \& Weiner, B. (1993). An attributional analysis of students’ interactions: The social consequences of perceived responsibility. Educational Psychology Review, 5, 325-345.

Killen, M., Crystal, D. S., \& Watanabe, H. (2002). Japanese and American children’s evaluations of peer exclusion, tolerance of differences, and prescriptions for conformity. Child Development, 73, 1788-1802.

Langevin, M., Bortnick, K., Hammer, T., \& Wiebe, E. (1998). Teasing/bullying experienced by children who stutter: Toward development of a questionnaire. Contemporary Issues in Communication Science and Disorders, 25, 12-24.

Law, G. U., Sinclair, S., \& Fraser, N. (2007). Children’s attitudes and behavioural intentions towards a peer with symptoms of ADHD: Does the addition of a diagnostic label make a difference? Journal of Child Health Care, 11, 98-111.

Nabors, L., \& Keyes, L. (1995). Preschoolers’ reasons for accepting peers with and without disabilities. Journal of Developmental and Physical Disabilities, 7, 335-355.

Nowicki, E. A., \& Sandieson, R. (2002). A meta-analysis of school-age children's attitudes toward persons with physical or intellectual disabilities. International Journal of Disability, Development and Education, 49, 243-265.

Puhl, R. M., \& Latner, J. D. (2007). Stigma, obesity, and the health of the nation's children. Psychological Bulletin, 133, 557-580. 
Robertson, D. L., Farmer, T. W., Fraser, M. W., Day, S. H., Duncan, T., Crowther, A., \& Dadisman, K. A. (2010). Interpersonal competence configurations and peer relations in early elementary classrooms: Perceived popular and unpopular aggressive subtypes. International Journal of Behavioral Development, 34, 73-87.

Sonnentag, T. L., Barlett, N. D., Livengood, J. L., Barnett, M. A., \& Witham, R. Y. (May, 2009). Children's perceptions of and anticipated responses to peers with various undesirable characteristics. Poster presented at the meeting of the Association for Psychological Science, San Francisco.

Swaim, K. F., \& Morgan, S. B. (2001). Children’s attitudes and behavioral intentions toward a peer with autistic behaviors: Does a brief educational intervention have an effect? Journal of Autism and Developmental Disorders, 31, 195-205.

Tiggemann, M., \& Anesbury, T. (2000). Negative stereotyping of obesity in children: The role of controllability beliefs. Journal of Applied Social Psychology, 30, 1977-1993.

Townsend, M. A. R., Wilton, K. M., \& Vakilirad, T. (1993). Children’s attitudes toward peers with intellectual disability. Journal of Intellectual Disability Research, 37, 405-411.

Vaillancourt, T., \& Hymel, S. (2006). Aggression and social status: The moderating roles of sex and peer-valued characteristics. Aggressive Behavior, 32, 396-408.

Weiner, B. (1986). An attributional theory of motivation and emotion. New York: SpringerVerlag.

Whalen, C. K., Henker, B., Dotemoto, S., \& Hinshaw, S. P. (1983). Child and adolescent perceptions of normal and atypical peers. Child Development, 54, 1588-1598.

Zeller, M. H., Reiter-Purtill, J., \& Ramey, C. (2008). Negative peer perceptions of obese children in the classroom environment. Obesity, 4, 755-762. 


\section{Footnotes}

${ }^{1}$ As in the Barnett et al. (2010) study, only descriptions of male peers with undesirable characteristics were presented to the children because of concerns involving limited sample size. As in the prior investigation, the extent to which the present findings were influenced by using only male peers in the descriptions provided to the children cannot be determined.

${ }^{2}$ The internal reliability for the aggregate anticipated response measure was lower for children's responses to the extremely aggressive peer $(\alpha=.63)$ than for any of the other five peers with undesirable characteristics ( $\alpha$ s ranging from .71 to .86). Although children may have anticipated displaying their disdain for the aggressive peer by not liking or helping him, they likely realized that it may be unwise to tease an aggressive peer.

${ }^{3}$ The six D/E/O patterns considered by participants in the present study are identical to those incorporated in a prior experiment (Barnett et al., 2010) that varied the pattern of response reported by six hypothetical peers with undesirable characteristics. As in the prior study, two other possible patterns (i.e., NoD/E/S and NoD/E/F) were not included in the present study because it seemed unreasonable for a peer to have no interest in changing a characteristic and, then, to exert effort to change that characteristic.

${ }^{4}$ Although the participants' gender and age were not of particular interest in this study, these variables were included in the analyses of the children's responses to the six questionnaires. In the ANOVAs reported in the Results, younger ( $n=70$; Range: 8.08-11.00 years; $M$ age $=9.76$ years, $S D=0.83$ years $)$ and older $(n=67 ;$ Range: $11.08-14.58$ years; $M$ age $=12.57$ years, $S D=0.98$ years) age groups were determined by a median split on the children’s ages (initially computed in months based on the birthdates provided by the participants). 
As presented below, the participants’ gender did play a role in their anticipated responses to the hypothetical peers with undesirable characteristics described on the questionnaires. However, no age-related differences were found in any of the analyses reported below, suggesting that the 8- to 14-year-old participants were quite consistent in their patterns of beliefs about, and anticipated reactions to, the hypothetical peers.

${ }^{5}$ When the relationship between the children’s desire/effort/outcome expectation scores and their anticipated response scores to the six peers with undesirable characteristics were examined independently from the the children's fault attribution scores, the bivariate correlations were positive and significant for 16 of the 18 analyses ( $r$ s for the 18 analyses ranging from .14 to .50 ; mean $r$ for the 18 analyses $=.29$ ). When the relationship between the children's fault attribution scores and their anticipated response scores to the six peers with undesirable characteristics were examined independently from the children's desire/effort/outcome expectation scores, the bivariate correlations were negative and significant in all six analyses ( $r$ s ranging from -.41 to -.72; mean $r$ for the six analyses = -.56). 
Table 1

Descriptions of Hypothetical Peers Appearing on the Questionnaires

There is a boy about your age at another school who is a poor student. He is a slow reader and has difficulty with math, science, and English. He gets poor grades on tests and often does not know the correct answer when called on in class. (Poor Student)

There is a boy about your age at another school who is a poor athlete. He is a slow runner and has difficulty throwing and catching a ball. He tends to be clumsy and messes up a lot when playing sports. (Poor Athlete)

There is a boy about your age at another school who is extremely overweight. He is a lot heavier than other boys his height. He did not fit into any of the regular desks in his classroom, so his teacher had to find a larger desk for him. (Extremely Overweight) There is a boy about your age at another school who is extremely aggressive. He gets angry very easily and often yells and says mean things to classmates. He picks fights with children in the lunchroom and playground and often hits or kicks them. (Extremely Aggressive)

There is a boy about your age at another school who is extremely shy. He usually stays by himself during lunch and recess and does not talk with other children. If someone asks him a question, he keeps his head down and answers in a very quiet voice. (Extremely Shy)

There is a boy about your age at another school who has difficulty sitting still and paying attention. He has a hard time staying at his desk and is always moving around. He can only focus on an activity for a few minutes before getting distracted by something else. (ADHD)

Note. The label applied to each of the hypothetical peers in the text of this article appears in parentheses following each description. The peer descriptions presented to the child-participants did not include these labels. The order in which the descriptions of the six hypothetical peers were presented to the children was varied across the groups of participants. 
Table 2

Children's Mean Ratings of Peers with Various Undesirable Characteristics

\begin{tabular}{|c|c|c|c|c|c|c|c|}
\hline & $\begin{array}{c}\text { Poor } \\
\text { Student }\end{array}$ & $\begin{array}{c}\text { Poor } \\
\text { Athlete }\end{array}$ & $\begin{array}{l}\text { Extremely } \\
\text { Overweight }\end{array}$ & $\begin{array}{l}\text { Extremely } \\
\text { Aggressive }\end{array}$ & $\begin{array}{l}\text { Extremely } \\
\text { Shy }\end{array}$ & ADHD & $F^{*}$ \\
\hline Fault & $\begin{array}{l}1.96^{\mathrm{b}} \\
(1.02)\end{array}$ & $\begin{array}{l}2.50^{\mathrm{c}} \\
(1.12)\end{array}$ & $\begin{array}{r}3.70^{\mathrm{d}} \\
(1.09)\end{array}$ & $\begin{array}{l}4.90^{\mathrm{e}} \\
(.89)\end{array}$ & $\begin{array}{l}1.65^{\mathrm{a}} \\
(.85)\end{array}$ & $\begin{array}{l}2.32^{\mathrm{c}} \\
(.97)\end{array}$ & 261.96 \\
\hline $\begin{array}{l}\text { Anticipated } \\
\text { Response }\end{array}$ & $\begin{array}{l}4.99^{\mathrm{d}} \\
(.79)\end{array}$ & $\begin{array}{l}4.71^{\mathrm{c}} \\
(.89)\end{array}$ & $\begin{array}{l}4.45^{b} \\
(.95)\end{array}$ & $\begin{array}{l}2.88^{\mathrm{a}} \\
(1.04)\end{array}$ & $\begin{array}{l}5.19^{\mathrm{e}} \\
(.84)\end{array}$ & $\begin{array}{l}4.61^{\mathrm{c}} \\
(.79)\end{array}$ & 166.47 \\
\hline Desire & $\begin{array}{l}5.01^{\mathrm{d}} \\
(.92)\end{array}$ & $\begin{array}{r}5.02^{\mathrm{d}} \\
(.95)\end{array}$ & $\begin{array}{l}4.51^{\mathrm{b}} \\
(1.27)\end{array}$ & $\begin{array}{r}3.83^{\mathrm{a}} \\
(1.36)\end{array}$ & $\begin{array}{c}4.85^{\mathrm{C}} \\
(1.14)\end{array}$ & $\begin{array}{l}4.77^{\mathrm{C}} \\
(.89)\end{array}$ & 28.12 \\
\hline Effort & $\begin{array}{l}4.92^{\mathrm{d}} \\
(.97)\end{array}$ & $\begin{array}{l}4.98^{\mathrm{d}} \\
(.91)\end{array}$ & $\begin{array}{l}4.29^{\mathrm{b}} \\
(1.07)\end{array}$ & $\begin{array}{r}3.75^{\mathrm{a}} \\
(1.34)\end{array}$ & $\begin{array}{l}4.82^{\mathrm{d}} \\
(1.08)\end{array}$ & $\begin{array}{r}4.69^{\mathrm{c}} \\
(1.17)\end{array}$ & 43.06 \\
\hline Outcome & $\begin{array}{l}4.89^{\mathrm{d}} \\
(.95)\end{array}$ & $\begin{array}{l}4.84^{\mathrm{d}} \\
(.93)\end{array}$ & $\begin{array}{c}3.96^{\mathrm{b}} \\
(1.33)\end{array}$ & $\begin{array}{l}3.30^{\mathrm{a}} \\
(1.29)\end{array}$ & $\begin{array}{l}4.83^{\mathrm{d}} \\
(1.12)\end{array}$ & $\begin{array}{r}4.61^{\mathrm{c}} \\
(.91)\end{array}$ & 54.69 \\
\hline
\end{tabular}

Note. Standard deviations are in parentheses below respective means. Means in the same row with different superscripts differ at $p<.05$ as determined by LSD pairwise comparisons.

*All $F$ values for the main effect of Characteristic listed below had $(5,665)$ degrees of freedom and were significant at $p<.001$. 
Table 3

Boys' and Girls’ Mean Ratings of Their Anticipated Response to Peers with Various Undesirable Characteristics

\begin{tabular}{lcccccc}
\hline & $\begin{array}{c}\text { Poor } \\
\text { Student }\end{array}$ & $\begin{array}{c}\text { Poor } \\
\text { Athlete }\end{array}$ & $\begin{array}{c}\text { Extremely } \\
\text { Overweight }\end{array}$ & $\begin{array}{c}\text { Extremely } \\
\text { Aggressive }\end{array}$ & $\begin{array}{c}\text { Extremely } \\
\text { Shy }\end{array}$ & ADHD \\
\cline { 2 - 6 } Boys & & & & & & \\
& $4.82^{\mathrm{a}}$ & $4.36^{\mathrm{a}}$ & $4.34^{\mathrm{a}}$ & $2.80^{\mathrm{a}}$ & $4.98^{\mathrm{a}}$ & $4.43^{\mathrm{a}}$ \\
& $(.84)$ & $(.86)$ & $(1.01)$ & $(1.14)$ & $(.90)$ & $(.83)$ \\
Girls & $5.17^{\mathrm{b}}$ & $5.13^{\mathrm{b}}$ & $4.58^{\mathrm{a}}$ & $2.98^{\mathrm{a}}$ & $5.44^{\mathrm{b}}$ & $4.83^{\mathrm{b}}$ \\
& $(.68)$ & $(.74)$ & $(.86)$ & $(.90)$ & $(.70)$ & $(.67)$ \\
& & & & & & \\
\hline
\end{tabular}

Note. Standard deviations are in parentheses below respective means. Means in the same column with different superscripts differ at $p<.05$ as determined by a simple effects ANOVA conducted on Gender for each of the Characteristics. 
Table 4

Children's Mean Ratings of the Extent to Which They Disagreed or Agreed That Peers With Various Undesirable Characteristics Would Display D/E/S and D/E/F Patterns of Response

\begin{tabular}{|c|c|c|c|c|c|c|c|}
\hline Pattern & $\begin{array}{c}\text { Poor } \\
\text { Student }\end{array}$ & $\begin{array}{c}\text { Poor } \\
\text { Athlete }\end{array}$ & $\begin{array}{l}\text { Extremely } \\
\text { Overweight }\end{array}$ & $\begin{array}{l}\text { Extremely } \\
\text { Aggressive }\end{array}$ & $\begin{array}{l}\text { Extremely } \\
\text { Shy }\end{array}$ & ADHD & $F^{*}$ \\
\hline $\mathrm{D} / \mathrm{E} / \mathrm{S}$ & $\begin{array}{l}5.66^{\mathrm{c}} \\
(.56)\end{array}$ & $\begin{array}{l}5.63^{\mathrm{c}} \\
(.56)\end{array}$ & $\begin{array}{l}5.07^{\mathrm{b}} \\
(.88)\end{array}$ & $\begin{array}{l}3.99^{\mathrm{a}} \\
(1.56)\end{array}$ & $\begin{array}{l}5.68^{\mathrm{C}} \\
(.54)\end{array}$ & $\begin{array}{l}5.50^{\mathrm{C}} \\
(.70)\end{array}$ & 137.43 \\
\hline $\mathrm{D} / \mathrm{E} / \mathrm{F}$ & $\begin{array}{l}1.93^{\mathrm{a}} \\
(.76)\end{array}$ & $\begin{array}{l}2.04^{\mathrm{a}} \\
(.86)\end{array}$ & $\begin{array}{l}2.33^{\mathrm{b}} \\
(1.06)\end{array}$ & $\begin{array}{l}2.91^{\mathrm{C}} \\
(1.47)\end{array}$ & $\begin{array}{l}1.94^{\mathrm{a}} \\
(.86)\end{array}$ & $\begin{array}{l}2.06^{\mathrm{a}} \\
(.78)\end{array}$ & 30.01 \\
\hline
\end{tabular}

Note. Standard deviations are in parentheses below respective means. Means in the same row with different superscripts differ at $p<.05$ as determined by LSD pairwise comparisons.

$\mathrm{D}=$ Desire; $\mathrm{E}=$ Effort S = Success; $\mathrm{F}$ = Failure

*Both post hoc $F$ values listed below had $(5,1757)$ degrees of freedom and were significant at $p<.001$. 